\title{
Erratum to: ICT and Human Capital Spillover Effects in Achieving Sustainable East Asian Knowledge-Based Economies
}

\author{
Elsadig Musa Ahmed ${ }^{1}$
}

Published online: 14 March 2017

(C) Springer Science+Business Media New York 2017

\section{Erratum to: J Knowl Econ DOI 10.1007/s13132-016-0430-4}

The original version of this article unfortunately contained mistake. In the explanation of equation $3, \lambda$ and $\theta$ were in the wrong place. The correct presentation of explanation of equation 3 is given below.

$$
\Delta \operatorname{lnTFPit}=\Delta \operatorname{lnGDPit}-[\alpha \cdot \Delta \ln \mathrm{Kit}+\beta \cdot \Delta \ln \mathrm{Lit}+\lambda \cdot \Delta \ln \mathrm{ICTit}+\theta \cdot \Delta \ln \mathrm{HCit}]
$$

where the weights are given by the average value shares as follows:

$\Delta \operatorname{lnGDPit} \quad$ is the growth rate of output

$\alpha . \Delta \ln K i t \quad$ is the contribution of the aggragte physical capital

$\beta . \Delta \operatorname{lnLit} \quad$ is the contribution of the aggregate labor

$\lambda . \Delta \ln I C T$ it $\quad$ is the contribution of the ICT

$\theta . \Delta \ln H C$ it $\quad$ is the contribution of the human capital

$\Delta . \ln$ TFPit is the total factor productivity growth

The online version of the original article can be found at http://dx.doi.org/10.1007/s13132-016-0430-4.

Elsadig Musa Ahmed

elsadigmusa@yahoo.com; elsadig1965@gmail.com

1 Faculty of Business, Economics Unit, Multimedia University, 75450 Melaka, Malaysia 